\title{
Does the Ultrasound Diagnosis of Low-lying Placenta in Early Pregnancy Warrant a Repeat Scan?
}

\author{
Maj I J Page \\ $M B, M R C O G$, RAMC \\ Consultant Obstetrician \& Gynaecologist \\ Sgt S Wolstenhulme \\ DCR, DMU, RAMC \\ Ultrasonagrapher \\ British Military Hospital, Munster, BFPO 17.
}

SUMMARY: A retrospective analysis of 732 consecutive deliveries at this hospital was undertaken to see if the early (15-20 weeks) pregnancy ultrasound placental localisation was of value, and whether the diagnosis of low-lying placenta warranted a repeat scan.

The placental site was reported as normal in 413 pregnancies, as low-lying in 79 and was not recorded in 240 . None of the women with a low-lying placenta developed placenta praevia. There were no significant differences in pregnancy outcome between those women with a low-lying placenta and those in whom it was normally situated.

The ultrasound diagnosis of low-lying placenta between 15 and 20 weeks gestation does not warrant a repeat scan.

\section{Introduction}

Ultrasound examination of the pregnant uterus is now accepted as routine and is usually performed between 15 and 20 weeks gestation. At this examination fetal viability may be confirmed, fetal abnormalities detected, maternal abnormalities such as ovarian cysts discovered(1), the presence of a multiple pregnancy diagnosed, and most usefully the gestation can be assessed(2).

The location of the placenta may also be noted, but the value of this is debated. Following King's observations(3) in 1973 that an apparently low-lying placenta in early pregnancy should be viewed as an anatomical variant, Chapman et al(4) stated that the ultrasound diagnosis of placenta praevia should not be made in an otherwise normal patient before 34 weeks gestation as the lower segment will not be properly formed. This view is supported by LOGIC(5) which noted that placental localisation in the second trimester is a difficult and often clinically confusing exercise, and suggests that only if the 'praevia' is complete should the scan be repeated in addition, of course, to those where it is symptomatic (i.e. bleeding). However Ellis(6) recently recommended that all women with an apparently low-lying placenta on early scan should have a repeat scan early in the third trimester to exclude placenta praevia.

This study assessed the predictive value of the early ultrasound diagnosis of low-lying placenta in our practice with regard to the development of placenta praevia or other obstetric abnormalities.

\section{Patients and Methods}

The notes from 732 consecutive deliveries at this hospital in 1988 were reviewed and details of the early
(15-20 weeks) pregnancy ultrasound localisation of the placenta were recorded.

In this unit the ultrasonographer performed the examinations using a Phillips SDR 1550 real-time system@ with a $3 \mathrm{MHz}$ sector or $4 \mathrm{MHz}$ linear transducer. The relationship of the lower edge of the placenta to the internal cervical os was determined by visualising them both on the same longitudinal section. Placental site at this early scan was variously documented as fundal anterior upper, posterior upper, anterior, posterior anterior low-lying, posterior low-lying or overlying the os. The last three have been classified as 'low-lying' in the subsequent analysis with the others classified as normal.

There is a degree of subjective bias in defining minor degrees of low-lying placenta, due to variability of distension of the maternal bladder and in defining the lower edge of the placenta, but in all cases the ultrasonographer (in his interpretation of the ultrasound appearances) recommended that a repeat scan for placental site should be performed later in the pregnancy.

The number of repeat scans performed as a direct consequence of this recommendation was ascertained, although not all women for whom a repeat scan was recommended actually had one.

Smoking and parity were noted to see if they affected the incidence of low-lying placenta in early pregnancy, and the outcome of all the pregnancies was reviewed to determine whether there was any correlation with the documented placental site.

\section{Statistical Methods}

The Chi-squared test was used for analysis when all three placental site groups (low, normal, unknown) 
were considered or where the outcome was divided into more than two groups. The 2-sided P-value from Fisher's Exact Test was used where two proportions were compared, with $95 \%$ confidence intervals for the difference in proportions.

A significant result is indicated by a $P$-value of $<0.05$ or a confidence interval excluding zero.

\section{Results}

Four hundred and ninety-two of the deliveries studied had had an ultrasound scan performed between 15 and 20 weeks gestation in which the placental site was stated. In $413(83.9 \%)$ of them it was normally sited and in 79 $(16.1 \%)$ it was low-lying. The placental site was not documented in 240 cases, having been performed elsewhere or outside the specified period of gestation.

Figure 1 shows the distribution of scans for each week of gestation, with the percentage of low-lying placentas each week shown in Table 1 . The differences are not significant. Sixty six further scans were performed between 27 and 37 weeks gestation (Table 2) as a direct consequence of the early scan reporting a low-lying placenta. In three women the placenta was still low between 31 and 34 weeks, although none of them had any vaginal bleeding. In a further case the placenta was thought to remain low-lying at 36 weeks gestation but she also delivered vaginally without any bleeding.

Antepartum haemorrhage (APH) occurred in eight women where the placental site in early pregnancy was known and in two where it was not (Table 3). Of the eight, two initially had a low-lying placenta but had had a repeat scan showing a normally sited placenta prior to the bleed. The other six were recorded as having a normally sited placenta in early pregnancy, but one presented with a painless APH at 35 weeks gestation and repeat scan showed a placenta praevia which was confirmed at Caesarean section.

Table 4 relates pregnancy outcome to the early placental site. There is no significant association between placental site and smoking habit $(P>0.02$, chisquared test). When the unknown placental site group is excluded, there is a significantly higher incidence of lowlying placenta in parous women ( $P=0.03$, chi-squared test).

\section{Discussion}

The importance of not over-diagnosing placenta praevia by ultrasound in early pregnancy has been noted previously(2), when only 5 out of 225 initially low-lying placentas became praevia. This study showed an even lower percentage which remained low on the second scan, and none of them had an APH due to placenta praevia.

The theoretical value of knowing placental site before an APH occurs has been prompted by observations that there may be no warning haemorrhages in up to $20 \%$ of cases $(7,8)$ and that even a total placenta praevia may not bleed until labour starts(9). In some cases the warning

\section{Number of scans}

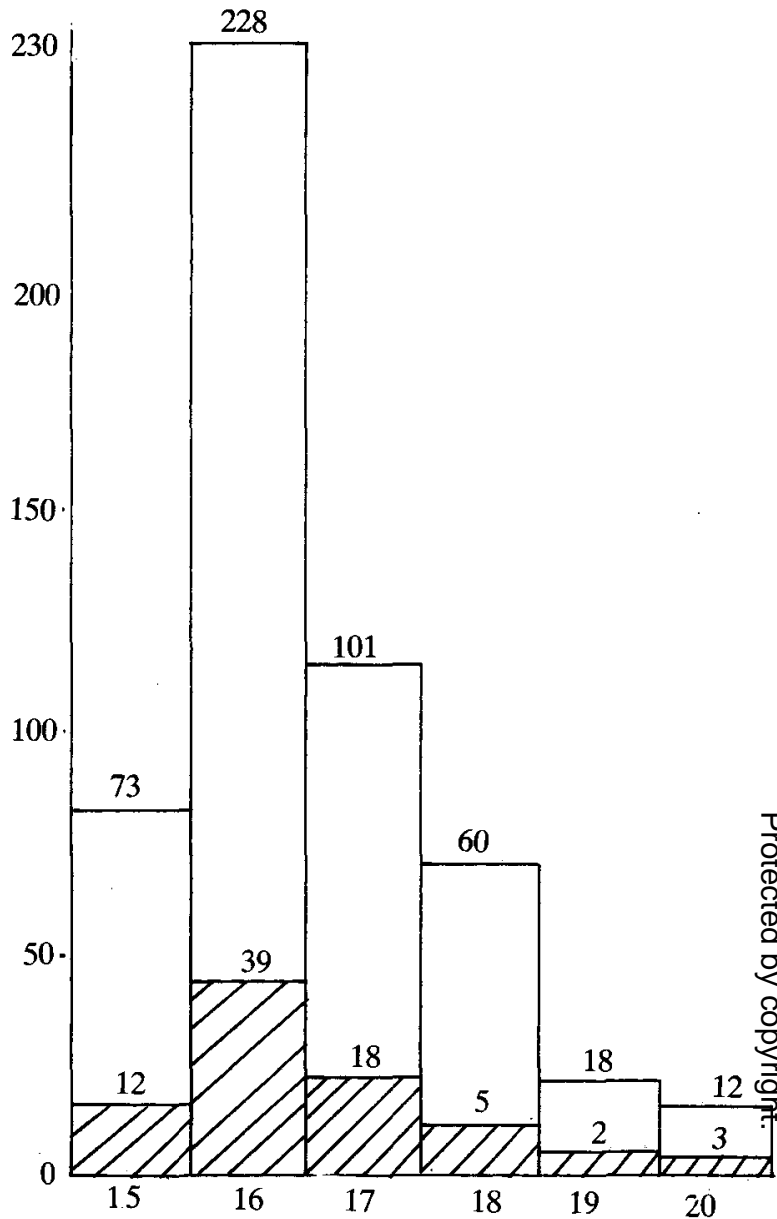

Gestation (weeks)

Fig 1. Distribution of scans by gestational age, showing proportion which are low-lying $(\beth)$.

Table 1

The incidence of low-lying placenta between 15 and 20 weeks gestation.

\begin{tabular}{cc}
\hline $\begin{array}{c}\text { Gestation } \\
\text { (weeks) }\end{array}$ & $\begin{array}{c}\text { Placentas 'low-lying' } \\
\%\end{array}$ \\
\hline 15 & 16.4 \\
16 & 17.1 \\
17 & 17.8 \\
18 & 8.3 \\
19 & 11.1 \\
20 & 25.0 \\
\hline
\end{tabular}


Table 2

Gestation of subsequent scans, where the initial scan showed a low-lying placenta.

\begin{tabular}{cccc}
\hline & \multicolumn{3}{c}{ Gestation (weeks) } \\
Placental site & $\mathbf{2 7 - 3 0}$ & $\mathbf{3 1 - 3 4}$ & $\mathbf{3 5 - 3 7}$ \\
\hline Normal & 28 & 29 & 4 \\
Low & $1^{*}$ & 3 & $1^{*}$ \\
Total & 29 & 32 & 5 \\
\hline
\end{tabular}

*Same case, vaginal delivery, no APH.

Table 3

Placental site, diagnosis and outcome of cases of APH.

\begin{tabular}{|c|c|c|c|c|}
\hline Case & $\begin{array}{l}\text { First Scan } \\
\text { Placental site } \\
\text { and gestation* }\end{array}$ & $\begin{array}{l}\text { Second Scan } \\
\text { Placental site } \\
\text { and gestation* }\end{array}$ & $\begin{array}{c}\text { Gestation } \\
\text { at APH }\end{array}$ & $\begin{array}{l}\text { * Diagnosis \& } \\
\text { delivery }\end{array}$ \\
\hline 1 & Normal-15 & - & - & $\begin{array}{l}\text { Uncertain } \\
\text { Normal - 39 }\end{array}$ \\
\hline 2 & Low, post -18 & Upper, post-18 & 32 & $\begin{array}{l}\text { Abruption } \\
\text { Normal - } 33\end{array}$ \\
\hline 3 & Normal-17 & Praevia-35 & 35 & $\begin{array}{l}\text { Praevia } \\
\text { LSCS-36 }\end{array}$ \\
\hline 4 & Normal-15 & Fundal-28 & 28 & $\begin{array}{l}\text { Uncertain } \\
\text { Normal-39 }\end{array}$ \\
\hline 5 & Normal-16 & Fundal-31 & 31 & $\begin{array}{l}\text { Abruption } \\
\text { Normal-34 }\end{array}$ \\
\hline 6 & Normal-16 & - & 34 & $\begin{array}{l}\text { Uncertain } \\
\text { Normal-40 }\end{array}$ \\
\hline 7 & Low, post $\rightarrow 16$ & Upper, post -28 & 33 & $\begin{array}{l}\text { Abruption } \\
\text { Normal-33 }\end{array}$ \\
\hline 8 & Normal-18 & Upper, post -27 & 39 & $\begin{array}{l}\text { Uncertain } \\
\text { Normal-39 }\end{array}$ \\
\hline 9 & Normal-23 & - & 38 & $\begin{array}{l}\text { Uncertain } \\
\text { Normal-38 }\end{array}$ \\
\hline 10 & Normal-23 & Normal-27 & 30 & $\begin{array}{l}\text { Uncertain } \\
\text { Normal-38 }\end{array}$ \\
\hline
\end{tabular}

*Completed weeks

Post $=$ posterior

Uncertain $=$ no definite diagnosis reached

haemorrhages that do occur precede 28 weeks gestation(10) and so may be ignored. In a retrospective study(11), where placenta praevia was diagnosed by finding the amniotomy hole to be within $3 \mathrm{cms}$ of the placental margin, $40 \%$ of women with placenta praevia who delivered vaginally had not had any vaginal bleeding during the pregnancy. Hence the intervention based on the scan alone would be of no benefit to at least $40 \%$ of the population identified as at risk.

The only intervention that can be offered is hospitalisation until the placenta appears on scan to be out of the lower segment or until haemorrhage necessitates delivery. Review of the Confidential
Enquiries into Maternal Deaths(12) since their inception in 1952 has not shown any deaths which would definitely have been prevented by ultrasound derived fore-warning of placenta praevia.

It would be more appropriate to educate pregnant women, and their attendants, that bleeding in pregnancy (particularly after 20 weeks gestation) is abnormal and should be reported. Many women are worried by the knowledge that they have a low-lying placenta, and some obstetricians make this worse by advising against foreign travel and sexual intercourse until the repeat scan has excluded a placenta praevia. This medicalises a normal pregnancy quite unnecessarily, as does admission of a probably multiparous woman to hospital just because of the scan appearances. The social implications of hospital admission for a mother, who is apparently fit and well, should not be forgotten.

Varma(13) showed an increased incidence of fetal growth retardation in her patients with placenta praevia as did Chapman et al(4) in their patients with a low-lying placenta on early scan. Our study has not shown this, and like Wexler and Gottesfeld(14) we found no other pregnancy abnormalities associated with a low-lying placenta.

An ultrasound scan costs approximately $£ 35$, ino 음 addition to the cost to the patient in time and trav $\rightarrow$ costs. Sixty-six repeat scans were performed during this

Table 4

Features and outcome of the 732 pregnancies

\begin{tabular}{|c|c|c|c|}
\hline \multirow[t]{2}{*}{$\overline{\text { Feature }}$} & \multicolumn{3}{|c|}{ Placental Site } \\
\hline & $\begin{array}{c}\text { Low } \\
(n=79)\end{array}$ & $\begin{array}{c}\text { Normal } \\
(\mathrm{n}=413)\end{array}$ & $\begin{array}{l}\text { Unknown } \\
(\mathrm{n}=240)\end{array}$ \\
\hline Smoking: Yes & 22 & 146 & 89 \\
\hline No & 54 & 249 & 136 \\
\hline Unknown & 3 & 18 & 15 \\
\hline Parity: 0 & $29^{*}$ & 209 & 117 \\
\hline$\geqslant 1$ & $50^{*}$ & 204 & 123 \\
\hline APH: all causes & 2 & 6 & 2 \\
\hline placenta praevia & 0 & 1 & 0 \\
\hline Fetal distress in labour & 2 & 18 & 8 \\
\hline Hypertension in pregnancy & 1 & 21 & 8 \\
\hline Preterm delivery (<37 weeks) & 4 & 13 & 1 \\
\hline Term birthweight: $\quad<2500 \mathrm{~g}$ & 1 & 17 & 4 \\
\hline $2501-3000 \mathrm{~g}$ & 13 & 57 & 49 \\
\hline$>3000 \mathrm{~g}$ & 61 & 326 & 186 \\
\hline
\end{tabular}

\begin{tabular}{ccc} 
& \multicolumn{2}{c}{ Placental Site } \\
Low & Other \\
Mode of delivery: & $(\mathrm{n}=79)$ & $(\mathrm{n}=653)$ \\
Spontaneous & 72 & 570 \\
Forceps or Ventouse & 3 & 47 \\
LSCS: in labour & 3 & 14 \\
elective & 1 & 22 \\
\hline
\end{tabular}

*The incidence of low-lying placenta is significantly higher $\left(\mathrm{P}=0.03, \mathrm{x}^{2}\right.$ test $)$ in parous women. 
year, making a total of $£ 2,300$ effectively wasted over 732 deliveries. For a unit delivering 3000 women anually this would increase to about $£ 10,000$ - almost the salary of a junior staff midwife.

As we have shown no benefit from knowing the placental site in early pregnancy, nor from repeating the scan later on, we suggest that routine repeat scans should not be performed for placental site alone indeed it may be better not to report placental site at all in early pregnancy, and to revert to treating patients according to their symptoms rather than treating their investigations(15).

\section{Acknowledgements}

We are grateful to the midwives at BMH Munster for their help with data retrieval, and to Mrs Margaret Sims at MOD Stats for statistical advice.

\section{REFERENCES}

1. O'Donovan P, Gupta J K, Savage J, Thornton J G, LILFORD $R$ J. Is routine antenatal booking vaginal examination necessary for reasons other than cervical cytology if ultrasound examination is planned? Br J Obstet Gynaecol 1988; 95: 556-559.

2. Campbell S, Little D. The current status of fetal heart rate monitoring and ultrasound in obstetrics. RCOG: London, 1977: 138-150.

3. KING D L. Placental migration demonstrated by ultrasonography. A hypothesis of dynamic placentation. Radiology 1973; 109: 167-170.
4. Chapman M G, Furness E T, Jones W R, Sheat J H. Significance of the ultrasound location of placental site in early pregnancy. Br J Obstet Gynaecol 1979; 86: 846-848.

5. LOGIC-Obstetrics Part 1, Q. 71. RCOG, London.

6. Ellis C. Routine ultrasound in pregnancy. In: Spencer J, ed. Fetal Monitoring; physiology and techniques of antenatal and intrapartum assessment. Kent: Castle House Publications, 1989: 37-40.

7. Macafee C H. Placenta praevia. Postgrad Med J 1962; 38 : 254-256.

8. Morgan J. Placenta praevia: report on a series of 538 cases (1938-1962). J Obstet Gynaecol Br Comm 1965; 72: 700705.

9. Myerscough P. Munro Kerr's Operative Obstetrics. 10th ed. London: Bailliere-Tindall, 1982: chapter 29.

10. Sсотт J S. Antepartum haemorrhage. In: Whitfield C R, ed. Dewhurst's Textbook of Obstetrics and Gynaecology for Postgraduates, 4th ed. London: Blackwell, 1986: 188-199.

11. Beischer N A, Mackay E V. Antepartum haemorrhage. In: Obstetrics and the Newborn. 2nd ed. London: Bailliere-Tindall, 1986: 157-168.

12. Reports on Confidential Enquiries into Maternal Deaths in England and Wales, 1952-1984. London: HMSO, 19571989.

13. VARMA T R. Fetal growth and placental function in patients with placenta praevia. $J$ Obstet Gynaecol $\mathrm{Br}_{\mathrm{O}}$ Comm 1973; 80: 311-315.

14. Wexler P, GotTesfeld K R. Second trimester placenta praevia. An apparently normal placentation. Obstet Gynecol 1977; 50; 706-709.

15. Anon. Routine diagnostic testing. Lancet 1989; ii: $1190-\vec{\sigma}$ 1191. 